Citizenship has three definitions: who or what we are, what we believe, and what we do, English explains: "The service-learning projects provide teachable moments, opportunities for reflection and the means to gain experience in community building."'

This is the fifth year California 4-H servicelearning grants have been awarded; distributions have ranged from $\$ 5,500$ to $\$ 14,900$ per year and are a gift from the Thomas and Dorothy Leavey Foundation. Proposed projects must contain aspects of community service and education; address significant environmental, economic and/or social issues affecting California's youth, families and communities; and involve collaboration with other community-based organizations.

Grants for four other service-learning projects were awarded in 2007. Another Siskiyou County 4-H group received $\$ 1,000$ to organize a "senior prom" for elderly residents. In Sacramento County, a 4-H club has $\$ 2,000$ to provide environmental education and outdoor living experience to 1,000 elementary students from economically disadvantaged neighborhoods. In San Mateo County, members of the Belmont 4-H Clothing Project were awarded \$233 to create dyed-silk scarves for a local hospital. Also, $\$ 500$ of seed money was awarded for surely the most ambitious youth service-learning idea ever, the 4-H Million Trees project.

The Pacifica 4-H club is developing plans to plant a million trees across the United States to combat global warming; their estimated budget for the project is $\$ 1$ million. High-school freshman Laura Webber saw Al Gore's An Inconvenient Truth with her father last winter and was galvanized to do something; she and the other club members worked out the details.

Although the Pacifica group will plant some trees, the aim of the project is to enlist the help of the 90,000 other 4-H clubs in the country, a total of 7 million youth. Each club has to plant only 12 trees to achieve the goal (www.4hmilliontrees.org).

Engaging in public projects that serve the community, or the whole world, in tangible, recognizable and important ways motivates young people (see page 40 ). The projects inspire their adult leaders also. Todd Ellorin, the Siskiyou Woodworking project leader says, "These kids want to know where the lumber is coming from and how the project affects the environment. I really learn from them."

The Siskiyou Land Trust listened to Boerger's new bench ideas "and made some changes," Boerger says. Ellorin says he will discuss with the group a way to respect the client's wishes and also try something new. That's another skill that's definitely useful for the adult world. - Hazel White

-

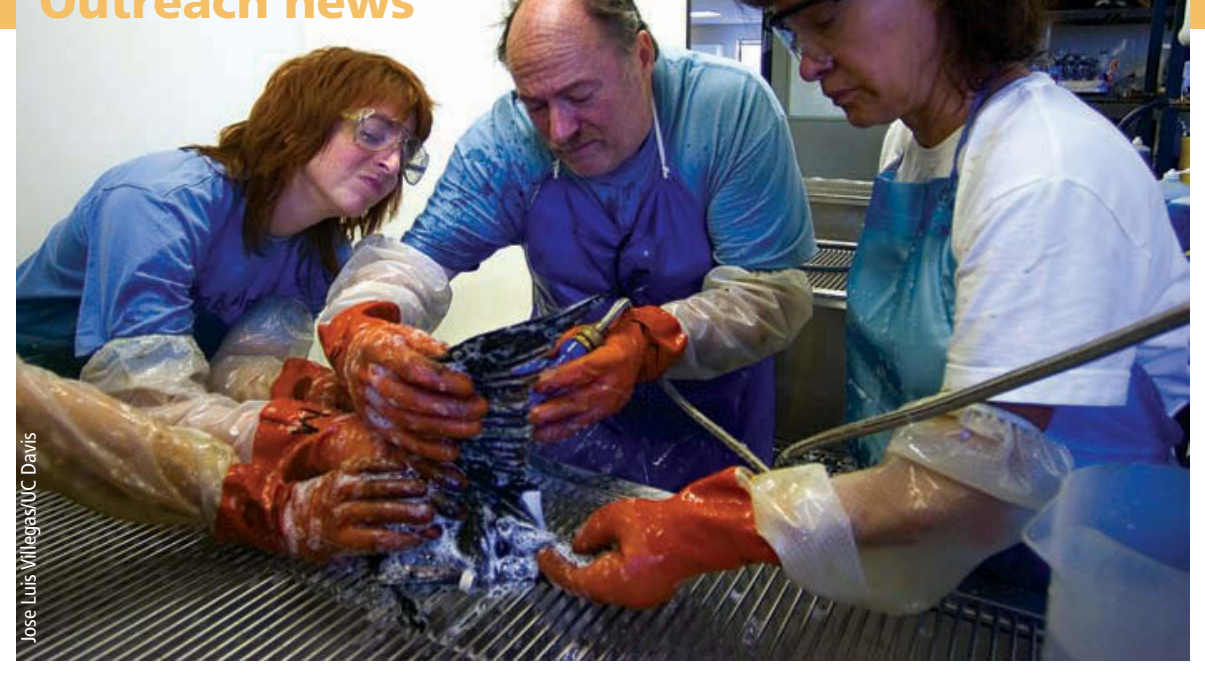

\title{
Oiled birds cleaned up and sent home; research studies launched
}

$T^{\text {hes }}$ 7 he 58,000-gallon oil spill in San Francisco Bay on Nov. 7, 2007, was the worst in a decade, and weeks later rescuers were still collecting coated birds from beaches. The oiled birds - primarily grebes, scaups and surf scoters - were brought to the Cordelia facility of the Oiled Wildlife Care Network, which comprises 25 organizations and a dozen facilities from Crescent City to San Diego, and is directed by UC Davis wildlife veterinarian Michael Ziccardi.

Saving oiled birds is far from a sure thing. "They arrive cold and weak because oil coats their feathers, forcing them to come out of the water to survive," Ziccardi says. Many die before they can even be cleaned, and more die in the rehabilitation pools prior to release. By the end of November, more than a thousand birds had been collected, nearly 800 had been washed, and more than 340 had been rehabilitated and released in Tomales and Half Moon bays, which lie beyond the reach of the oil spill. Nearly 1,750 birds were collected dead, and about 600 died or were euthanized in captivity.

The Cordelia center - called the San Francisco Bay Oiled Wildlife Care and Education Center — is a 12,000-square-foot, $\$ 2.7$ million facility capable of caring for between 1,000 and 1,500 sick birds, and is co-managed by the International Bird Rescue Center. The Oiled Wildlife Care Network is funded by the California Department of Fish and Game, with interest on the $\$ 50$ million California Oil Spill Response Trust Fund built from assessments on the oil industry.

\section{Studies aimed at survival of oiled birds}

Little is known about what happens to the relatively few birds lucky enough to make it back to the wild, but Ziccardi and his colleagues are trying to find out. The veterinarians are implanting about 25 oiled and rehabilitated birds and an equal number of $\triangle$ After the November 2007 oil spill in the San Francisco Bay, staff and volunteers with the Oiled Wildlife Care Network washed about 800 oiled birds at their Cordelia facility. 


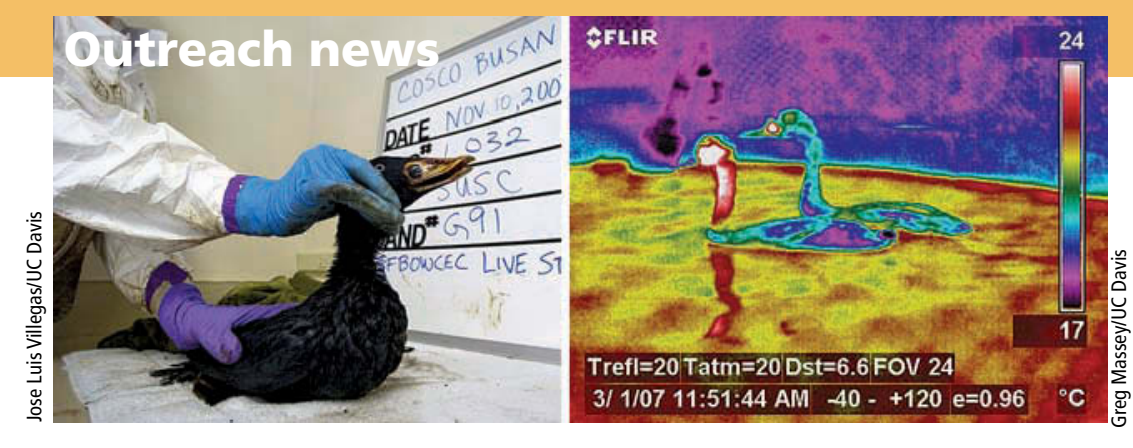

Above left, an oiled bird. Above right, UC Davis researchers will test the use of infrared thermography to take the temperature of oiled birds. Bird on right is cold (blue neck and head); bird on left is warm (red neck). whether cleaned birds are still losing body heat, and control birds with tiny backpack-style radio transmitters so their whereabouts and survival can be tracked.

The team is also launching several new studies aimed at increasing the survival of oiled birds. These include using infrared thermography to determine identifying the causes of anemia, which is common in birds that ingest oil. A related project will determine whether various blood tests can predict survival. “The oiled birds' blood will be analyzed for hemoglobin, which might be a better indicator for anemia in dehydrated birds, as well as fibrinogen, a protein indicative of inflammation," Ziccardi explains.

To better protect the birds' health, tests will be conducted on the air, water, hard surfaces and feeding tubes in the rescue center for a mold called Aspergillus. To better protect the rescue workers' health, tests will be done for the presence of zoonotics - disease-causing organisms that can travel from animals to humans - such as Salmonella and Campylobacter.

The studies will be led by Ziccardi and UC Davis spill response veterinarian Greg Massey. The research teams will include veterinary and postgraduate students at the UC Davis School of Veterinary Medicine, as well as scientists from the U.S. Geological Survey, U.S. Fish and Wildlife Service, California Department of Fish and Game's Office of Oil Spill Prevention and Response (OSPR), and Humboldt State University.

"We want to take advantage of this tragic spill to gather as much information as possible so that we can improve our effectiveness and save more birds in the future," Ziccardi says

$$
\text { - Robin Meadows and Editors }
$$

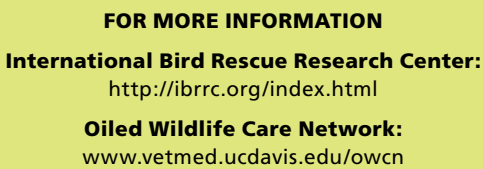

\section{UC Cooperative Extension helps people cope with Southern California wildfires}

\begin{abstract}
$\Gamma$ he wildfires that devastated Southern California in October 2007 came only 4 short years after the region's previous catastrophic burn, which was in October 2003. These two firestorms had many similarities, with both being fanned by hot, dry Santa Ana winds, and both ultimately burning hundreds of thousands of acres. But there was also a key difference: UC Cooperative Extension made it easier for people to cope with wildfire the second time around.

"After the 2003 fires, we realized that we didn't have a way to help people during and after a fire," says Terry Salmon, director of San Diego County Cooperative Extension. "There was lots of information but it wasn't centralized."
\end{abstract}

\section{Wildfire Web site}

To fix this problem, Salmon and his colleagues developed a comprehensive wildfire Web site called the Wildfire Zone. The site has three main sections explaining what to do before, during and after a fire, and was adapted from a University of Nevada Cooperative Extension Web site. The project was in collaboration with the County of San Diego, and received funding from the County as well as the Federal Emergency Management Agency.
Fortuitously, the Wildfire Zone was finished just in time for the 2007 fires. "It hadn't even been advertised, and it got 300,000 hits the day after the first fire," says Salmon, adding that the Web site was also useful to the county Office of Emergency Services. San Diego got the worst of the fires, which burned 380,000 acres there in a week, forcing the evacuation of half a million people and destroying well over a thousand homes.

People accessing the new Web site got immediate practical information. For example, before evacuating, they should help firefighters by filling garbage cans with water, propping a ladder against the roof, and turning on all the lights to make the house easier to find in the smoke. In addition, people could enter their ZIP code to find out which emergency number to call. "It's confusing because there are so many fire departments in the county," Salmon says.

\section{Fire-safe homes}

The Wildfire Zone's initial focus was on how to prepare for fires. "You can do a lot to protect your house from a wildfire," says Stephen Quarles, a wood durability advisor at Contra Costa County Cooperative Extension. The Web site has step-bystep advice on retrofitting houses to reduce their 